\title{
A aquisição do princípio C da teoria de ligação em português brasileiro: questões metodológicas
}

The acquisition of principle $\mathrm{C}$ of binding theory in Brazilian Portuguese: methodological issues

\author{
Elaine Grolla \\ Universidade de São Paulo
}

\section{Resumo}

A distribuição de expressões referenciais nas línguas naturais é regulada pelo princípio C. Assume-se que tal princípio é universal, sendo operativo em todas as línguas naturais. O objetivo principal deste estudo é investigar o conhecimento que as crianças (em idade pré-escolar, entre 4;0 e 6;6 anos, adquirindo o português brasileiro) possuem acerca desse princípio. Mais especificamente, objetivamos investigar a aquisição do princípio C por meio de duas metodologias distintas: a tarefa de julgamento de gramaticalidade (TJG) e a tarefa de julgamento de valor de verdade (TJVV). Isso se justifica na medida em que alguns autores argumentam que a TJVV não é indicada para o estudo da aquisição do princípio C. Portanto, ao usar as duas metodologias para testar as mesmas estruturas com as mesmas crianças, pudemos checar potenciais diferenças no comportamento delas nos dois métodos. De modo geral, os resultados sugerem que as crianças possuem conhecimento sobre o princípio $\mathrm{C}$, rejeitando casos clássicos de violação desse princípio. Os resultados também sugerem que a TJVV é apropriada para se investigar tal princípio. 


\section{Palavras-chave}

Princípio C, metodologias experimentais, catáfora, anáfora.

\section{Abstract}

The distribution of referential expressions in natural languages is regulated by the Principle C. It is generally assumed that this principle is universal, operating in all languages. The goal of this study is to investigate children's knowledge about the Principle C. Our subjects are Brazilian Portuguese-speaking children ranging from $4 ; 0$ to $6 ; 6$ years. More specifically, we investigate the acquisition of Principle $\mathrm{C}$ by means of two different methods: the grammar judgment task (GJT) and the truth-value judgment task (TVJJ). This is intended to address some critiques found in the literature arguing that the TVJJ might not be appropriate for testing Principle C cases. Using two methods for testing the same structures with the same children, we were able to check potential differences in children's behavior by using these two methods. In general, the results suggest that children from 4;0 on display knowledge about Principle $\mathrm{C}$, since they rejectviolations of the principle. The results also suggest that the TVJJ is appropriate for testing this principle.

\section{Keywords}

Principle C, experimental methodologies, backward anaphora, forward anaphora. 


\section{Introdução}

\subsection{Objetivos e hipóteses}

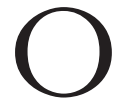

objetivo principal desta pesquisa é investigar a aquisição do princípio C da teoria de ligação (CHOMSKY, 1981) em crianças em idade pré-escolar, entre 4 anos e 6 anos e 6 meses de idade, adquirindo o português brasileiro (PB) como língua materna. Mais especificamente, nosso objetivo é investigar a aquisição do princípio $\mathrm{C}$ por meio de duas metodologias distintas: a tarefa de julgamento de gramaticalidade (TJG) e a tarefa de julgamento de valor de verdade (TJVV), discutidas em detalhes adiante.

Outro objetivo da pesquisa é checar se a tarefa de julgamento de valor de verdade é apropriada para se testar tal conhecimento, dada a alegação feita em Lust, Eisele e Mazuka (1992)de que tal teste induziria a criança ao acerto, por meio de pistas extralinguísticas. Ao conduzir testes usando tanto a TJVV como a TJG, compararemos as respostas das mesmas crianças nos dois casos para o mesmo fenômeno. Esperamos que as crianças se comportem de forma semelhante nos dois testes. Se encontrarmos crianças que frequentemente aceitam as sentenças com violações do princípio C na TJG, mas as rejeitam na TJVV, teremos evidência de que a TJVV é realmente inapropriada. No entanto, nossa hipótese é de que tal divergência não ocorrerá e que as crianças mostrarão conhecimento sobre o princípio $\mathrm{C}$ nos dois tipos de teste.

O artigo está organizado da seguinte maneira: na próxima subseção, apresentamos o quadro teórico que embasa nossa pesquisa. Na seção 2, discutimos estudos anteriores que investigaram a aquisição do princípio $\mathrm{C}$ e as metodologias empregadas em cada um. Na seção 3, discutimos em detalhe as metodologias usadas na presente pesquisa. Na seção 4, apresentamos o estudo experimental por nós realizado. A seção 5 é a conclusão. 


\subsection{Quadro teórico}

Nas línguas naturais, a referência a entidades do mundo é realizada por expressões referenciais (expressões-R) (p. ex., "a mesa", "o João"), pronomes (p. ex., "ele", "elas") e anáforas (p. ex., "se", "nos"). As anáforas e os pronomes são elementos que não possuem referência própria e, para referir, necessitam de um nome. As expressões referenciais, como o nome indica, referem sem depender de outro elemento para isso. Quando esses elementos se encontram dentro de sentenças, existem algumas restrições em suas distribuições. Neste trabalho, adotamos a Teoria de Princípios e Parâmetros (cf. Chomsky, 1981), Chomsky (1986) e Chomsky e Lasnik (1993)), que propõe que a distribuição desses elementos é regulada pela Teoria de Ligação, composta por três princípios, a saber: A, B e C. O princípio A lida com a distribuição de anáforas, o princípio $\mathrm{B}$, com a distribuição de pronomes e o princípio $\mathrm{C}$ lida com a distribuição de expressões-R. Esses princípios, expostos abaixo, são tidos como sendo universais, operativos em todas as línguas naturais (CHOMSKY, 1981):

(1) a.Princípio A: Uma anáfora deve ser ligada em seu domínio de regência ${ }^{\mathrm{i}}$.

b.Princípio B: Um pronome deve ser livre em seu domínio de regência. c.Princípio C: Uma expressão-R deve ser livre.

O princípio A exige que uma anáfora tenha um antecedente (que a ccomande e esteja coindexado a ela) em seu domínio de regência. Já o princípio $\mathrm{B}$ exige dos pronomes uma restrição inversa: eles não podem ter um antecedente em seu domínio de regência. O princípio C é ainda mais restritivo e pró́be expressões-R de possuírem um antecedente não só em seu domínio de regência, mas em qualquer oração em que elas se encontrem. Os exemplos abaixo ilustram como esses princípios funcionam:

a. A Maria $\mathrm{se}_{\mathrm{i}}$ admira.

b. * A Maria ${ }_{\mathrm{i}}$ acha que o João $\mathrm{K}_{\mathrm{k}} \mathrm{se}_{\mathrm{i}}$ admira. 
a. * A Maria ${ }_{\mathrm{i}}$ admira ela $\mathrm{i}_{\mathrm{i}}$

b. A Maria ${ }_{i}$ acha que o João ${ }_{k}$ admira ela .
a. * Ela admira a Maria $_{i}$.
b. *Ela disse que o João admira a Maria $_{i}$.

Em (2a), temos a anáfora "se", que é correferente a "Maria". A anáfora está ligada pelo DP “a Maria” em seu domínio de regência (o que está em conformidade com o princípio A), e a sentença é gramatical. No entanto, em (2b), o antecedente e a anáfora não estão no mesmo domínio. Por conter uma anáfora não ligada em seu domínio de regência, a sentença não é gramatical. Em (3a), o pronome é localmente ligado por "a Maria”. Isso viola o princípio B, e a sentença é agramatical. Por outro lado, em (3b), o antecedente para o pronome não se encontra no mesmo domínio, e a sentença é boa. Em (4a),a expressão-R "a Maria" é c-comandada pelo pronome "ela" e está coindexada com esse pronome,ou seja, o pronome liga a expressão-R, fazendo com que ela não seja livre, constituindo uma violação do princípio C. (4a) não pode significar que a Maria se admira. Aqui o pronome deve ter uma interpretação exofórica, tomando como referente um indivíduo não mencionado na sentença, mas saliente no discurso. O mesmo ocorre em (4b), que ilustra o fato de que o grau de encaixe da sentença não é relevante para o princípio C: uma expressão-R não pode ter um antecedente em sua oração ou numa oração matriz.

Uma questão crucial a ser observada diz respeito à ordem linear dos elementos na sentença. Para detectar se uma expressão-R está ligada ou não por determinado elemento, devemos checar, além da coindexação, se ela é c-comandada ou não por tal elemento. A ordem linear com relação a esse elemento não é relevante. O contraste abaixo ilustra esse ponto:

(5) a. * Ela ${ }_{\mathrm{i}}$ foi cozinhar quando a Maria $\mathrm{i}_{\mathrm{i}}$ terminou de limpar a casa. b. Quando ela $\mathrm{i}_{\mathrm{i}}$ terminou de limpar a casa, a Maria $\mathrm{f}_{\mathrm{i}}$ foi cozinhar.

Ambas as estruturas possuem o pronome "ela" linearmente à frente da expressão-R “a Maria”. Em (5a), a expressão-R é c-comandada pelo pronome, o 
que constitui uma violação do princípio C. Já em (5b), a oração adjunta está movida para o início da sentença, e o pronome, dentro dela, não c-comanda a expressãoR. Portanto, não há ligação e, por conseguinte, violação do princípio. A sentença é gramatical. As estruturas podem ser vistas esquematicamente nas árvores a seguir (detalhes omitidos):

a. *

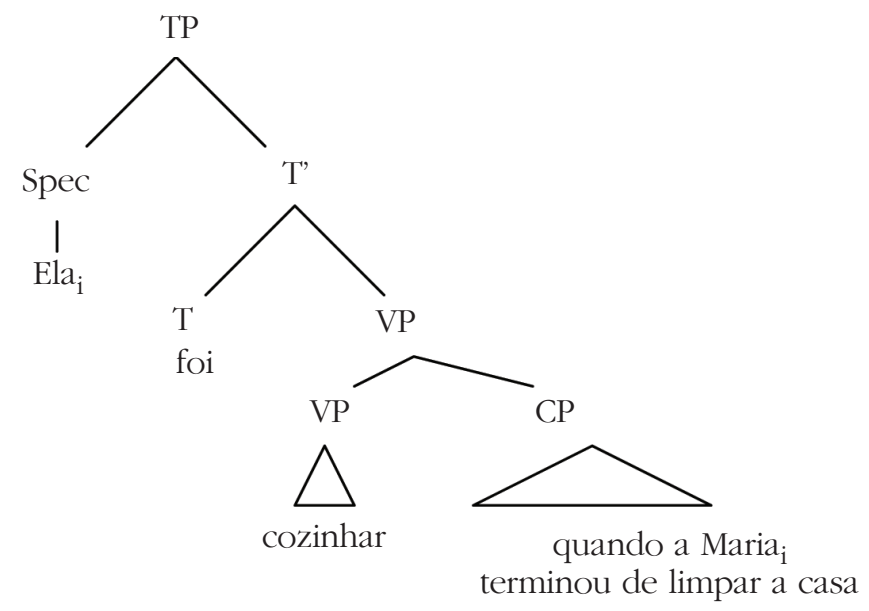

b.

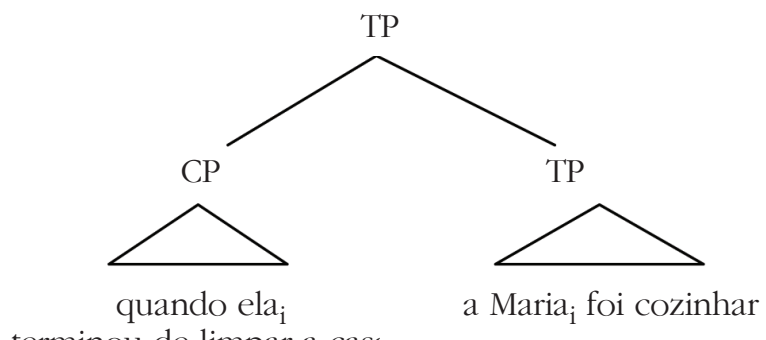

terminou de limpar a casá

A Teoria de Princípios e Parâmetros postula que os princípios A, B e C, por serem universais, fazem parte do conhecimento linguístico com a qual a criança nasce. É nesse contexto que a presente pesquisa se insere, buscando evidências sobre o conhecimento linguístico da criança. 


\section{O conhecimento das crianças sobre o princípio $C$ - resultados e metodologias de estudos anteriores}

Se o conhecimento sobre os princípios de ligação é inato, então devemos ser capazes de observá-lo em crianças muito jovens, em idade pré-escolar. No entanto, o comportamento das crianças com relação ao princípio C é muito debatido na literatura internacional. A razão para esse debate se deve à divergência de resultados dos estudos a esse respeito.

Em estudos mais recentes (por exemplo, Crain e McKee (1985), Thornton e Wexler (1999), Conroy e Thornton (2005) e Adler (2006)), crianças adquirindo inglês foram estudadas usando-se a tarefa de julgamento de valor de verdade (TJVV - truth-value judgment task - ver descrição detalhada dessa metodologia adiante), e elas acertaram mais de 85\% dos casos. No entanto, em estudos mais antigos (também em inglês), as crianças foram testadas em outros métodos (como a tarefa de encenação ou de imitação) e acertaram menos de 40\% dos testes (cf., dentre outros, Lust, Loveland e Kornet (1980); Solan (1978) e Tavakolian (1977)).

Acreditamos que essa divergência de resultados seja devida a problemas nas metodologias empregadas pelos estudos mais antigos. A maioria dos estudos mais recentes, usando a TJVV, aprimorou as técnicas experimentais e conseguiu aumentar a taxa de acerto das crianças, fazendo com que elas rejeitassem a maioria das violações de princípio C. No entanto, Lust, Eisele e Mazuka (1992) fazem uma crítica a tal método, questionando se tal "aprimoramento" na técnica não acabou por influenciar o comportamento das crianças, levando-as a rejeitar as violações não porque elas sabiam o princípio, mas porque a pragmática do discurso usado nos testes da TJVV era orientada para a rejeição.

É por conta desse impasse que, neste estudo, tratamos de forma especial essa questão metodológica, procurando testar se as críticas feitas às metodologias mais recentes para a investigação sobre a aquisição do princípio C procedem. Dessa forma, este trabalho contribui para o debate sobre a aquisição do princípio C em geral, que, como apontado, é uma questão ainda sem consenso na literatura internacional. 
Estudos mais antigos sobre a aquisição do princípio C, tais como Lust et al. (1980), Solan (1978) e Tavakolian (1977), indicam que as crianças não possuem conhecimento sobre esse princípio. Observe as sentenças abaixo usadas no teste de Lust et al. (1980):

a. * He said that Bert touched the box.

"* Ele disse que o Bert tocou na caixa"

b. Because he heard a lion, Tommy ran fast.

"Porque ele ouviu um leão, o Tommy correu depressa"

Em ambas as sentenças, o pronome está linearmente posicionado à frente da expressão-R. Embora (7a) seja um caso de violação do princípio C, (7b) não éii. Lust et al. (1980) testaram 82 crianças entre 3;5 e 7;5 de idade (a idade é expressa em anos;meses)usando uma tarefa de manipulação (act-out task) e uma tarefa de imitação estimulada (elicitedimitationtask).

As crianças se comportaram de maneira semelhante quando os dois tipos de sentenças foram testados, rejeitando ambos por volta de $70 \%$ das vezes. Portanto, alguns dos estudos citados, como Solan (1978) e Tavakolian (1977), propuseram que as crianças podem ter rejeitado ( $7 \mathrm{a}$ ) não por causa do seu conhecimento do princípio em questão, mas por causa de um efeito de direcionalidade, quer dizer, as crianças parecem rejeitar qualquer caso em que o pronome antecede a expressão-R, mesmo os casos que são aceitáveis na língua adulta.

No entanto, Thornton e Wexler (1999) rejeitam tal conclusão. Esses autores acreditam que esses resultados são fruto de problemas metodológicos dos estudos. Eles notam que os estudos que indicam um efeito de direcionalidade usaram ou tarefas de manipulação ou tarefas de imitação estimulada. No caso de tarefas de manipulação, em que as crianças têm de manipular brinquedos encenando a sentença que ouviram, as crianças atribuíam ao pronome em sentenças como (7a) a referência de um segundo personagem não mencionado na sentença quando manipulando os brinquedos. Thornton e Wexler observam que isso não implica que as crianças não sabem o princípio C; essa escolha apenas reflete a preferência das crianças por um referente dêitico alternativo. 
No caso das tarefas de imitação estimulada, as crianças algumas vezes evitavam repetir (7b) literalmente, preferindo a ordem inversa entre pronome e expressão$\mathrm{R}$, como em "porque o Tommy ouviu um leão, ele correu depressa". Thornton e Wexler notam que esse comportamento tem sido incorretamente analisado como demonstrando que as crianças não permitem casos de catáfora. Eles mencionam as observações feitas em Lasnik e Crain (1985) que notam que as crianças não seriam capazes de rearranjar as sentenças desse modo se elas não tivessem um entendimento das relações de coreferência.

Estudos mais recentes sobre a aquisição do princípio C utilizam a tarefa de julgamento de valor de verdade (TJVV), que é amplamente utilizada não só para testar a aquisição de princípio $C$, mas também vários outros fenômenos linguísticos, como quantificadores universais (Crain (1991); Crain et al (1996)), sentenças-donkey (Crain, Conway e Thornton (1994); Conway e Crain (1995); Crain et al (1996)), passivas (Gordon e Chafetz (1986); O’Brien, Grolla e LilloMartin (2005)), dentre outros. No entanto, Lust et al (1992) questionam a eficácia dessa metodologia para se testarem sentenças com violação do princípio C. Consideremos primeiramente o estudo de Crain e McKee (1985), que apresentou pela primeira vez tal metodologia do modo como ela é utilizada em estudos mais recentes. Crain e McKee testaram sentenças como as seguintes:

(8) When she was outside playing, Strawberry Shortcake ate an icecream cone.

"Quando ela estava lá fora brincando, moranguinho comeu um sorvete."

$$
\text { a. *He washed Luke Skywalker. }
$$

* Elelavou Luke Skywalker.

b. *He ate the hamburger when the Smurf was in the fence.

* Ele comeu o hambúrguer quando o Smurf estava na cerca.

62 crianças entre 3 e 6 anos de idade foram testadas usando-se a TJVV. As crianças corretamente aceitaram (8) 73\% das vezes e rejeitaram sentenças como (9a) e (9b) 88\% das vezes. 
Como ilustração, consideremos como esse experimento foi usado no contexto da história contada para as crianças antes de (9b) ser usada. A história continha dois personagens: Smurf e Gargamel. Gargamel diz que não comerá um hambúrguer porque ele odeia hambúrgueres, mas Smurf os adora e come um enquanto está num cercadinho. O raciocínio de Crain e McKee era o seguinte. Se as crianças sabem o princípio C, elas não interpretarão o pronome e o nome "Smurf" como sendo correferentes na sentença, uma vez que isso violaria o princípio. A única interpretação possível para essa sentença para o adulto tem o pronome como referindo-se a um outro indivíduo que não Smurf. Gargamel, sendo o outro personagem da história, é o referente mais acessível. Se o pronome se referir a Gargamel, (9b) é falsa, porque Gargamel não comeu o hambúrguer, apenas o Smurf comeu. Portanto, na interpretação do adulto, a sentença é falsa. Se a criança disser que a sentença é verdadeira, saberemos que ela atribuiu ao pronome a interpretação de Smurf, violando o princípio $C^{\mathrm{iii}}$.

Como mencionado, as crianças corretamente rejeitaram (9b) $88 \%$ das vezes, indicando que elas sabem o princípio C. Lust et al. (1992), no entanto, argumentam que a metodologia usada por Crain e McKee pode ter levado as crianças ao acerto por razões independentes do conhecimento do princípio C. Lust et al. observam que existe uma outra possibilidade para explicar por que as crianças rejeitaram sentenças como (9b). Eles notam que a maneira como a história foi contada pode ter deixado Gargamel muito saliente no contexto, fazendo dele o antecedente mais natural para o pronome. Se esse for o caso, a resposta negativa das crianças não implica que elas sabem o princípio C; ela apenas indica que as crianças foram atentas à proeminência de Gargamel na história.

É por conta desse impasse que a presente pesquisa se propõe a testar as crianças em duas metodologias distintas, discutidas a seguir.

\section{Metodologias empregadas no presente estudo}

Para checar a eficácia da TJVV nos testes, no presente trabalho comparamos essa metodologia a outra amplamente utilizada em estudos em aquisição 
da linguagem, mais precisamente, a tarefa de julgamento de gramaticalidade (TJG). Na TJG, seguindo a metodologia desenvolvida por Hiramatsu e Lillo-Martin (1998), a criança é apresentada a um fantoche, que é manipulado por um dos experimentadores. O boneco às vezes fala as coisas de um jeito errado ou esquisito, porque ele ainda está aprendendo a língua da criança: a tarefa da criança é ajudar o boneco a aprender sua língua. Se o fantoche diz algo do "jeito certo", a criança deve lhe dar uma bolacha de chocolate (de plástico), sua comida preferida, como prêmio. Se ele diz algo do "jeito errado", a criança deve lhe dar uma fruta (que o deixa mais inteligente). O experimentador apresenta figuras (contendo personagens de histórias infantis) para a criança e para o fantoche. O fantoche tenta descrever o que está acontecendo nas figuras (no nosso caso, por meio de sentenças com violações de princípio C), e a criança tem de dizer se as sentenças enunciadas pelo fantoche são aceitáveis ou não. Por exemplo, em uma das figuras apresentadas às crianças de nosso estudo, tem-se um elefante se lavando. O fantoche descreve a cena dizendo: "Essa figura tem um elefante em um lago. Ele está lavando o elefante.”. A tarefa da criança é dizer se essa sentença é aceitável, dado o contexto da figura. Nesse caso, a sentença será julgada como errada pela criança que tiver conhecimento do princípio C.

Na TJVV, a criança também é entrevistada individualmente numa sala em que somente a criança e o experimentador estão presentes. Aqui o fantoche, diferentemente do boneco da TJG, sabe a língua da criança, mas é muito distraído. No caso de nosso estudo, um outro boneco foi apresentado às crianças como alguém que sabe a língua delas, mas que algumas vezes não presta atenção nas figuras e diz algo que não está acontecendo nelas por ser muito distraído. A criança então checa se o que ele disse realmente aconteceu na história (verdadeiro) ou não (se ele ficou distraído e disse algo que não aconteceu).

Nesse tipo de experimento, o que está em jogo não é se a sentença dita pelo fantoche é aceitável ou não (como na TJG), mas se ela é verdadeira ou não, baseada no contexto apresentado à criança por meio de figuras de personagens de histórias infantis. As sentenças testadas têm duas interpretações: em uma delas a sentença é verdadeira, e na outra ela é falsa. A resposta da criança indica qual leitura ela deu à sentença. Uma das histórias usadas em nosso 
experimento é apresentada a seguir:

Experimentador: Nessa história, a Cinderela e a madrasta foram a um baile no castelo do príncipe. Na hora de ir embora, a madrasta desceu a escada desajeitada e quase que um sapato saiu do pé dela, mas não saiu. Mas a Cinderela estava com muita pressa e, quando ela descia a escada, o sapatinho dela ficou lá.

Fantoche: Já sei o que aconteceu! Ela perdeu o sapatinho quando a Cinderela desceu a escada.

Criança: Verdadeiro/Falso.

Note-se que a sentença é verdadeira na interpretação em que ela = Cinderela e falsa na interpretação em que ela = madrasta. Se a criança disser que a sentença é verdadeira, isso indicará que ela interpretou o pronome como se referindo à Cinderela, o que implica que ela violou o princípio C. Se a criança disser que a sentença é falsa, isso indicará que, muito provavelmente, ela interpretou o pronome como se referindo à madrasta, não violando, portanto, o princípio C.

Na próxima seção, apresentamos o estudo experimental em detalhes.

\section{Estudo experimental}

\subsection{Condições testadas}

Com o intuito de obter um panorama completo sobre o conhecimento da criança no que tange ao princípio C, é relevante veri-ficarmos o comportamento da criança não só em casos clássicos de violação do princípio, como (10a) a seguir, mas também em casos em que a expressão-R, e o pronome estão em orações distintas, como (10b). Além disso, temos que checar se a criança permite casos aceitáveis de catáfora, como (10c). Nessa estrutura, o pronome vem à frente da expressão-R, mas não a c-comanda, situação que não constitui, portanto, uma violação ao princípio C. Se as crianças respeitam a estrutura hierárquica das sentenças e não se baseiam em sua ordem linear, elas devem aceitar tais sentenças mais frequentemente do que aceitam (10a) e (10b). 
(10) Condições testadas

a. Pron ER: * Ele $e_{i}$ está lavando o elefante .

b. Pron ER (enc): * Ele $_{i}$ buzinou quando o cachorro ${ }_{i}$ andou de carro.

c. Catáfora: Quando ela $a_{\mathrm{i}}$ terminou de limpar a casa, a pata foi cozinhar.

Para realizar a pesquisa, foram incluídas duas sentenças de cada condição para cada um dos testes, TJG e TJVV, ou seja, para cada criança, temos quatro respostas para cada condição ( 2 na TJG e 2 na TJVV), totalizando doze res-postas para cada criança. As sentenças utilizadas podem ser encontradas no anexo deste artigo.

\subsection{Sujeitos}

Foram entrevistadas 20 crianças, sendo que 3 delas tiveram de ser retiradas das análises dos resultados por não terem passado os critérios estabelecidos de antemão, que são explicitados mais abaixo. Tendo excluído essas crianças, ficamos com 17 sujeitos, entre 4;4 e 6;2 anos de idade. A idade média do grupo é de 5;2 anos. São 8 crianças entre 4;4 e 4;10 anos; 7 crianças entre 5;1 e 5;11 e 2 crianças com mais de 6 anos (6;1 e 6;2). Na análise dos dados que é efetuada a seguir, incluímos as crianças de 6 anos no grupo das crianças de 5 anos, por conta do número reduzido de sujeitos naquela faixa etária. Como são apenas duascrianças, e elas tinham acabado de completar 6 anos, acreditamos que a inclusão delas no grupo de crianças de 5 anos não acarretará nenhum problema à análise.

Na primeira sessão de cada um dos testes, as crianças aprendiam a tarefa em questão (treinamento) e eram avaliadas para se ter certeza de que elas a haviam entendido(pré-teste). No pré-teste, 6 sentenças foram testadas: 3 aceitáveis e 3 inaceitáveis, sendo que nenhuma delas envolvia o fenômeno a ser estudado, ou seja, nenhuma delas continha violações do princípio C. Foram formuladas sentenças simples em que a resposta das crianças podia ser prevista. Como critério para passar o pré-teste e ser incluída no estudo, a criança tinha que rejeitar as 3 sentenças inaceitáveis e aceitar pelo menos 2 das sentenças 
aceitáveis $^{\text {iv }}$. Além disso, ao longo do teste, foram incluídas sentenças distratoras, que atuaram como controles: a criança que aceitasse uma sentença distratora agramatical ou rejeitasse uma sentença controle gramatical seria excluída do estudo. Duas das crianças excluídas aceitaram todas as sentenças distratoras agramaticais inseridas na sessão de testes e uma das crianças aceitou uma sentença agramatical do período de pré-teste, sendo excluída antes mesmo do início dos testes.

\subsection{Métodos}

Checar se a crítica de Lust et al. (1992) realmente procede é um dos objetivos desta pesquisa. A ideia é comparar as respostas que as crianças deram quando a TJVV foi usada com as respostas dadas quando a TJG foi usada. Neste trabalho, as duas metodologias são diferenciadas pelo tipo de figura utilizado nos testes. Para a TJG, a condição "Pron ER", por exemplo, continha apenas um personagem realizando uma ação reflexiva. Um dos itens desta condição continha um cachorro se coçando. Nesse caso, o experimentador apresentava a figura do seguinte modo:

(1) Tarefa de julgamento de gramaticalidade - TJG:

Experimentador: Nessa figura, temos um cachorrinho e ele está com coceira. Diz o que está acontecendo nessa figura, Luno.

Luno (fantoche): Ele tá coçando o cachorro.

Criança: Certo/errado.

Na sentença dita pelo fantoche, a referência do pronome não é ambígua: ela pode se referir apenas ao cachorro, já que não há outro personagem na figura. A tarefa da criança é dizer se o que o fantoche disse é um jeito "esquisito" ou não para descrever a cena (visto que o boneco não é fluente em PB), ou seja, confrontada com aquele contexto, a criança emitia um julgamento acerca da gramaticalidade da sentença proferida pelo fantoche aprendiz de PB. Usando a TJVV, o tipo de figura apresentado às crianças é diferente. Para testar a mesma condição "Pron ER", uma das sentenças utilizada foi "ele está lavando 
o elefante". A figura acompanhando essa sentença continha não um, mas dois personagens, um elefante em um lago se lavando e um urso olhando a cena. O experimentador apresentava a figura da seguinte maneira:

\section{(12) Tarefa de julgamento de valor de verdade - TJVV:}

Experimentador: Nessa figura, a gente tem o papai urso aqui e o elefante está no lago, tomando banho. Olha só o xampu dele e as espumas que ele está fazendo... O urso não está tomando banho, mas o elefante está lavando, olha lá.

Juquinha (fantoche): Já sei o que que tá acontecendo na figura! Ele tá lavando o elefante!

\section{Criança: Certo/errado.}

Na sentença do fantoche, o pronome poderia tomar sua referência de um dos dois personagens. Se a criança interpretasse ele = elefante (caso em que haveria violação do princípio C), a sentença dita pelo fantoche seria julgada como verdadeira. Se a criança interpretasse ele = urso (onde não há violação do princípio e a única interpretação possível para o adulto), a sentença seria julgada como falsa, porque o urso não estava lavando o elefante. Assim, a resposta da criança não nos indica se a sentença é gramatical ou não (como no caso da TJG); ela nos indica qual interpretação a criança deu ao pronome, sugerindo, por conseguinte, se houve violação do princípio.

Para todas as condições testadas, temos então dois tipos de figuras: uma em que a referência do pronome não é ambígua e ele só pode se referir ao mesmo indivíduo que a expressão-R e outra em que a referência do pronome é ambígua, pois há dois personagens na figura. No primeiro caso, temos o julgamento de gramaticalidade e, no segundo, o julgamento de valor de verdade.

\subsection{Resultados}

Reproduzimos a seguir os resultados na TJVV e na TJG para os dois grupos de crianças (G4 e G5+6), apresentando o total de aceitações para as condições 
testadas. Para as condições "Pron ER" e "PronER (enc)", essas são as respostas incorretas. Para a condição "catáfora" (sombreada), esta é a resposta correta:

\begin{tabular}{|l|c|c|c|c|}
\hline \multirow{2}{*}{} & \multicolumn{2}{|c|}{ G4 (N=8) } & \multicolumn{2}{c|}{ G5+G6 (n=9) } \\
\cline { 2 - 5 } & TJG & TJVV & TJG & TJVV \\
\hline 1 - Pron ER & $25 \%$ & $0 \%$ & $27.7 \%$ & $22.2 \%$ \\
\hline 2 - Pron ER (enc) & $56.2 \%$ & $56.2 \%$ & $55.5 \%$ & $50 \%$ \\
\hline 3 - Catáfora & $81.2 \%$ & $75 \%$ & $94.4 \%$ & $83.3 \%$ \\
\hline
\end{tabular}

Tabela 1: Taxás de aceitação para os grupos G4 e G5+G6.

\subsection{Discussão}

Iniciemos notando que as taxas de aceitação para a condição "Pron ER"

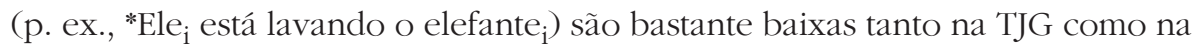
TJVV, abaixo de $30 \%$ para o grupo total de crianças. Para o grupo 4 , temos as taxas de $25 \%$ (TJG) e 0\% (TJVV). Para o grupo 5+6, temos $27.7 \%$ (TJG) e $22.2 \%$ (TJVV). Essas baixas taxas de aceitação sugerem que as crianças obedecem ao princípio C. Contrastando com essa baixa aceitação, temos os altos índices para a condição "Catáfora" (p. ex., Quando elai terminou de limpar a casa, a patai foi cozinhar). Para o grupo 4, temos 81\% (TJG) e 75\% (TJVV). Para o grupo 5+6, temos 94.4\% (TJG) e 83.3\% (TJVV). Esse contraste mostra que as crianças diferenciam casos aceitáveis de catáfora de casos inaceitáveis com violação do princípio C, ou seja, as rejeições para a condição "Pron ER" não podem ser atribuídas a uma preferência da criança pela ordem linear em que a expressão$\mathrm{R}$ vem à frente do pronome. Se assim fosse, elas deveriam igualmente rejeitar as sentenças da condição "Catáfora", o que não ocorreu.

No entanto, apesar desses resultados esperados para as condições "Pron ER" e "Catáfora", temos um resultado intrigante para a condição "Pron ER (enc)" (p. ex., "Ele buzinou quando o cachorro $_{\mathrm{i}}$ andou de carro). As crianças apresen- 
tam um índice relativamente elevado de aceitação desta estrutura, aceitando-a mais de 50\% das vezes nos dois métodos. O grupo 4 aceitou tal construção 56.2\% (TJG e TJVV) e o grupo 5+6 aceitou-a 55.5\% (TJG) e 50\% (TJVV), em um comportamento que pode ser considerado como de chance ${ }^{v}$. Esperávamos que a aceitação dessa condição fosse comparável aos índices para a condição "Pron ER”, já que elas são estruturalmente semelhantes, possuindo a expressão-R ligada por um antecedente. A única diferença entre elas é o grau de encaixe da sentença em que a expressão-R se encontra. Essa expectativa se baseava também em resultados de estudos anteriores. Crianças testadas em inglês, por exemplo, rejeitam essas estruturas a níveis comparáveis aos da condição "Pron ER", como no estudo de Crain e McKee (1985), discutido anteriormente em (9). Os resultados da presente pesquisa constituem, portanto, algo inesperado.

Um fator que pode ser relevante para explicar esses resultados se refere ao fato de que as sentenças utilizadas nessa condição possuem a oração encaixada iniciada com "quando",ou seja, as sentenças encaixadas são adjuntos das orações matrizes. Uma possibilidade que temos de considerar é de que orações adjuntas são de algum modo mais difíceis para as crianças do que as orações que são argumentos das orações matrizes (como "ele disse que o cachorro andou de carro").

Devemos notar que uma taxa em torno de 50\% de acerto é difícil de ser interpretada. Ela indicaria que a criança sabe ou não sabe o princípio C? De um lado, se elas não soubessem o princípio, por que aceitariam somente 50\% das violações e não 100\% delas? Por outro lado, se elas sabem o princípio, por que rejeitariam apenas 50\% das violações? Considerando a alta taxa de rejeição para a condição "Pron ER" (que sugere que a criança de fato obedece ao princípio C), propomos que se examine a alta taxa de erro para a condição "Pron ER (enc)" levando-se em conta o fato de que as orações testadas são adjuntas das orações matrizes e não seus argumentos.

Um dos possíveis problemas pode estar em se escolher o nó onde adjungir a oração. A seguir, fornecemos duas possibilidades: numa delas, a oração iniciada com "quando" é adjungida a TP"i e, na outra, ela é adjungida a VP: 
(13)

a
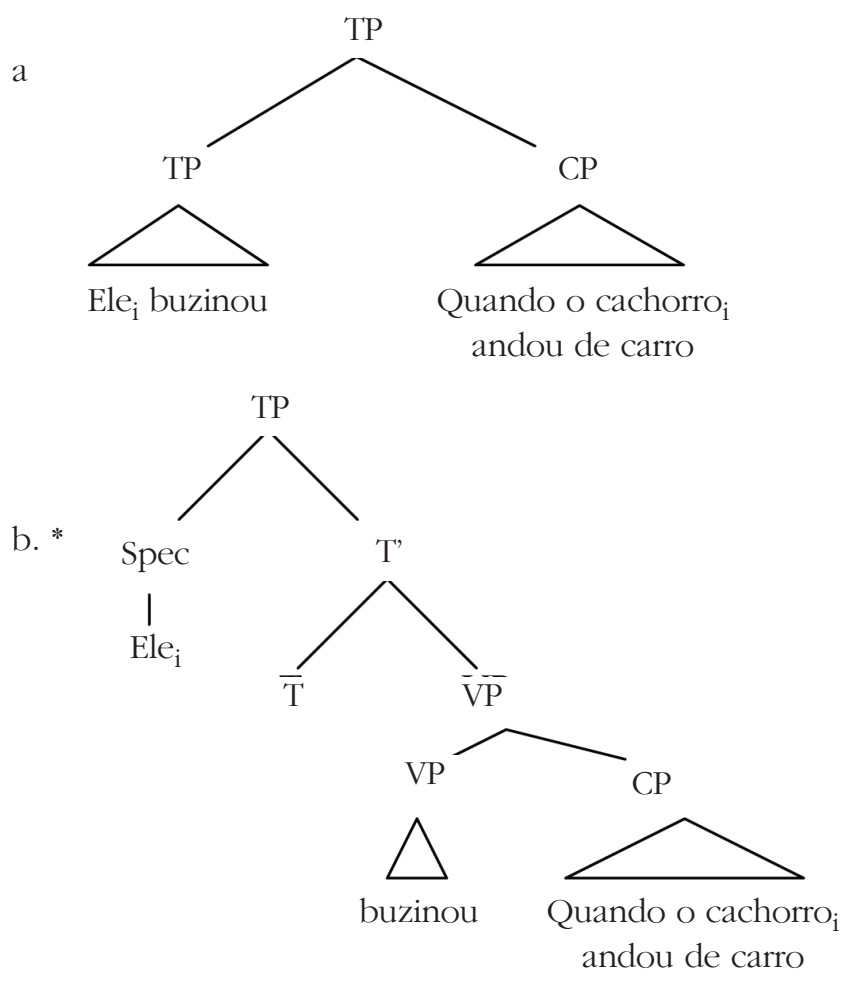

Em (13a), não há violação do princípio C, já que a expressão-R, contida numa oração adjungida a TP, não é c-comandada pelo pronome. Por outro lado, na estrutura em (13b), que seria a estrutura na língua adulta, há violação do princípio: a oração contendo a expressão-R é adjungida a VP, o que faz com que o pronome c-comande a expressão-R "o cachorro", ligando-a.

A taxa de aceitação da condição "Pron ER (enc)" pode se dever ao fato de a criança poder atribuir a orações desse tipo tanto a estrutura em (13a) como aquela em (13b),ou seja, a criança passaria por um período em que as duas estruturas são possíveis em sua gramática. Quando a estrutura em (13a) é acessada, as crianças aceitam a sentença com a interpretação em que a expressão- $R$ e o pronome partilham o mesmo referente. Quando a sentença recebe a estrutura em (13b), as crianças rejeitam a leitura com correferência. 
Evidência de que essa hipótese pode estar no caminho certo vem de três estudos sobre a aquisição de inglês: McDaniel, Cairns e Hsu (1991), Cairns, McDaniel, Hsu e Rapp (1994) e Adler (2006).

McDaniel et al. (1991) e Cairns et al. (1994) descobriram que crianças adquirindo inglês (com idades entre 3;10 - 4;11 anos) têm dificuldade com estruturas de controle em orações adjuntas. Inicialmente, tal dificuldade está também presente com orações complemento, mas ela logo desaparece e apenas as sentenças com orações adjuntas apresentam problemas para a interpretação de PRO. Esses tipos de estrutura são exemplificados a seguir:

a. Controle de objeto em complementos:

Ariel $_{\mathrm{i}}$ told Ernie $_{\mathrm{k}} \mathrm{PRO}_{\mathrm{k}}$ to buy ice cream.

"Ariel falou pro Ernie comprar sorvete"

\section{b. Controle de sujeito em complementos:}

Ariel $_{\mathrm{i}}$ promised Ernie $_{\mathrm{k}} \mathrm{PRO}_{\mathrm{i}}$ to buy an ice cream.

"Ariel prometeu pro Ernie comprar sorvete"

(15) Controle de sujeito em adjuntos:

Ariel $_{\mathrm{i}}$ kissed Ernie $_{\mathrm{k}}$ before $\mathrm{PRO}_{\mathrm{i}}$ buying an ice cream.

"Ariel beijou Ernie antes de comprar um sorvete"

Em (14a), PRO tem como controlador o objeto da oração matriz, Ernie, e a sentença tem a interpretação de que Ariel disse para o Ernie: "Ernie compre sorvete”. Já em (14b), PRO é controlado pelo sujeito da oração matriz e a sentença tem a interpretação de que Ariel fez a seguinte promessa a Ernie: "eu, Ariel, vou comprar sorvete". Em (15), a oração encaixada é adjunta, e não complemento, da oração matriz. Nesse caso, PRO só pode ser controlado pelo sujeito da oração matriz. A sentença tem a interpretação de que Ariel beijou Ernie antes de Ariel comprar um sorvete.

As crianças adquirindo inglês não tiveram comportamento uniforme na interpretação dessas sentenças, e quatro padrões de respostas foram detectados. 
No padrão A, as crianças apresentaram interpretação livre para PRO, escolhendo o sujeito, o objeto ou um personagem extralinguístico como o referente de PRO em orações complemento e adjunto. No padrão B, elas possuem interpretação livre de PRO somente em adjuntos. Nesse caso, as crianças já possuem comportamento adulto com relação a controle em orações complemento, mas ainda permitem interpretação livre de PRO em orações adjuntas. No padrão C, as crianças apresentam controle de objeto para PRO em orações adjuntas, tomando o objeto da matriz como antecedente para PRO (algo impossível para o adulto). Por fim, no padrão D, as crianças às vezes tomam o sujeito da matriz como antecedente para PRO em orações adjunto, como os adultos, mas algumas vezes elas tomam o objeto da matriz como controlador de PRO.

A explicação de McDaniel et al. para esse percurso de desenvolvimento é a "hipótese da estrutura modificante" (tradução nossa para structure-changinghypothesis): as crianças teriam estruturas diferentes ao longo do tempo, até que a estrutura adulta seja corretamente analisada. No caso do comportamento A, por exemplo, os autores sugerem que as crianças atribuem uma estrutura de coordenação à sentença, o que faria com que nenhum DP na oração matriz ccomandasse PRO na sentença encaixada. Nesse caso, PRO pode ter uma interpretação arbitrária ou ligada no discurso a qualquer um dos participantes. Num momento posterior, as crianças adquirem a estrutura subordinada, mas a oração adjunta pode ser colocada em nós diferentes da estrutura, dando origem a diferentes configurações e possibilidades de c-comando entre o sujeito e o objeto da matriz com relação a $\mathrm{PRO}^{\mathrm{vii}}$.

Adler (2006), retomando essa questão, aplica experimentos para testar essa mesma hipótese e chega a resultados semelhantes. Com um refinamento no tipo de conjunção usada nas sentenças-teste, Adler descobre que as crianças possuem problemas com as conjunções 'before' (antes) e 'after' (depois), mas não com 'without' (sem). A autora testa as mesmas crianças em casos de controle de PRO e em casos de violação do princípio C, e seus resultados mostram uma forte associação: as crianças que têm problemas com controle de PRO em sentenças com 'before' e 'after' também apresentam comportamento nãoadulto em sentenças com violação do princípio C em orações adjuntas. Sua conclusão é 
de que as crianças passam por um período em que elas não anexam a oração adjunta apropriadamente a VP. Elas provavelmente adjungem a oração num nó mais alto da estrutura, o que resulta em configurações em que PRO ou a expressão-R não são c-comandados por DPs da oração matriziii.

Voltando para o caso do PB, assumiremos que as respostas nãoadultas para a condição "PronER(enc)" advêm do fato de as crianças adjungirem a oração a um nó alto da estrutura, de modo análogo ao que acontece no inglês infantil. Nessa configuração, não há violação do princípio C, já que expressão-R não é c-comandada pelo pronome da oração matriz. Nesses casos, o pronome toma a referência da expressão-R, sendo que tal resolução de referência é realizada no discurso: o pronome toma a referência do elemento mais proeminente no contexto ${ }^{\mathrm{ix}}$. Nosso laboratório realiza no momento estudos que incluem não só sentenças com orações adjuntas, mas também orações completivas. Quando a oração é argumento do verbo (como em "Elei disse que o cachorroi andou de carro"), o seu local na estrutura não é ambíguo, e assim poderemos detectar mais fielmente se o problema das crianças é com orações encaixadas (o que as levaria a ter um comportamento nãodulto tanto em orações completivas quanto em orações adjuntas) ou com o nó para adjunção das orações adjuntas (nesse caso, as crianças apresentariam comportamento nãoadulto apenas com as orações adjuntas) ${ }^{\mathrm{x}}$. Resultados de um estudo piloto trazem argumentos a favor da segunda hipótese.

A hipótese que gostaríamos de discutir a seguir é a de ter havido uma maior rejeição quando a TJVV foi utilizada. Se o personagem extra presente nas figuras (que não estava realizando uma ação reflexiva) tivesse ficado mais proeminente e tivesse chamado a atenção das crianças, como hipotetizado por Lust et al (1992) para o estudo de Crain e McKee (1985), elas tomariam esse personagem como referente para o pronome, rejeitando as sentenças testadas,ou seja, a rejeição não se daria por causa do conhecimento do princípio C, mas por fatores pragmáticos, externos à gramática. Como essa possibilidade está ausente na TJG (que não possui um personagem extra), diferenças significativas nas respostas nas duas metodologias poderiam indicar que, realmente, a TJVV não é apropriada.

De modo geral, as taxas de rejeição são parecidas nas duas metodolo- 
gias. Para todas as condições testadas, encontramos um índice mais alto de rejeição na TJVV. No entanto, apesar de as rejeições serem maiores na TJVV, a diferença entre os resultados é pequena e não encontramos crianças que, individualmente, apresentaram um índice muito mais alto de rejeição para a TJVV do que para a TJG. Esses resultados sugerem, portanto, que a crítica de Lust et al. não procede. Para que tal crítica fosse corroborada, teríamos de achar índices significativamente mais altos na TJVV do que na TJG, o que não ocorreu.

É importante observar que os resultados aqui reportados contribuem para a literatura em aquisição de linguagem, pois indicam que os resultados até hoje obtidos em estudos utilizando-se a metodologia de TJVV são válidos, oferecendo respaldo para que ela continue a ser usada em pesquisas futuras.

\section{Conclusão}

Neste artigo, investigamos a aquisição do princípio C da teoria de ligação por crianças monolíngues, que estão adquirindo o PB como língua materna, entre 4;4 e 6;2 anos de idade.

Os resultados indicam que as crianças possuem conhecimento acerca do princípio em questão, pois elas rejeitaram a maioria das violações do princípio em sentenças simples, sem encaixamento (como "*Ele $e_{i}$ está lavando o elefante $_{i}$ "). Já nas sentenças encaixadas (como "*Ele $e_{i}$ buzinou quando o cachorro ${ }_{i}$ andou de carro"), as crianças apresentaram um comportamento de chance, rejeitando apenas a metade dos casos de violação. Tal comportamento não nos leva a concluir que as crianças não possuem conhecimento acerca do princípio C. Se assim fosse, elas deveriam aceitar tais sentenças 100\% das vezes, o que não ocorreu para nenhuma criança testada. A hipótese considerada neste artigo sustenta que as crianças, inicialmente, adjungem as orações a nós mais altos na estrutura, o que gera configurações em que a expressão-R, que está dentro da oração encaixada, não é c-comandada pelo pronome. Não havendo c-comando, não há ligação e, consequentemente, o princípio C não é violado. Nesses casos, o pronome receberia a mesma referência que a expressão- $\mathrm{R}$ através de correferência extrassentencial (e não através de ligação). Mais estudos são necessários 
para embasar essa análise, e eles estão em curso em nosso laboratório.

A comparação intermetodológica realizada nesta pesquisa não indica que a TJVV é inapropriada para testar o conhecimento das crianças sobre o princípio C, já que os índices de rejeição obtidos com a TJVV são comparáveis aos encontrados com a TJG, ou seja, as alegações de Lust et al não encontram confirmação em nossos resultados. A evidência trazida neste trabalho é particularmente interessante, já que os dois tipos de testes foram feitos com as mesmas crianças. Sendo assim, não há a possibilidade de que os comportamentos aqui reportados possam ser devidos a particularidades de diferentes populações testadas.

Por fim, notamos que nossos resultados trazem contribuições para a área de teoria gramatical, pois sugerem que as crianças possuem conhecimento sobre o princípio C, o que é desejável, já que esse princípio é tido como sendo universal. $\mathrm{O}$ estudo também contribui para a literatura em aquisição de linguagem, pois indica que os resultados até hoje obtidos por estudos que se utilizaram da metodologia de TJVV são válidos e que tal método pode continuar a ser usado em pesquisas futuras.

\section{Referências}

Adler, A. Syntax and Discourse in the Acquisition of Adjunct Control. 2006. Tese de doutorado. MIT, Cambridge.

Cairns, H., McDaniel, D., Hsu, J. Rapp, M. A Longitudinal Study of Principles of Control and Pronominal Reference in Child English. Language 70, 260-288. 1994. Chomsky, N. Lectures on Government and Binding. Dordrecht: Foris. 1981.

Chomsky, N. Knowledge of Language: Its Nature, Origin, and Use. New York: Praeger. 1986.

Chomsky, N., e Lasnik, H. The Theory of Principles and Parameters. In Syntax: An International Handbook of Contemporary Research. J. Jacobs, A. v. Stechow, W. Sternefeld e T. Vennemann (eds.). Berlin: de Gruyter. 1993.

Conway, L. e Crain, S. Donkey Anaphora in Child Grammar.Trabalho apresentado em NELS 25: Amherst, MA. 1995.

Conroy, S. e R. Thornton.Children's knowledge of Principle C in discourse.In 
Proceedings of the Sixth Tokyo Conference on Psycholinguistics. Y. Otsu (ed.), p. 69-94. Tokyo: HituziSyobo Publishing Company. 2005.

Crain, S. Language Acquisition in the Absence of Experience. Behavioral and Brain Sciences 14, 597-612. 1991.

Crain, S., Conway, L. e Thornton, R. D-Quantification in Child Language.TrabalhoapresentadoemESCOL 1994. Ithaca, NY: Cornell University. 1994.

Crain, S., e McKee, C. The Acquisition of Structural Restrictions on Anaphora.In Proceedings of the 16th North Eastern Linguistic Society, eds. S. Berman, J.W.Choe e J. McDonough. Amherst, MA: University of Massachusetts, GLSA. 1985. Crain, S. et. al. Quantification without Qualification.Language Acquisition 5, 83153. 1996.

Gordon, P. e Chafetz, J. Lexical Learning and Generalization in the Passive Construction.Trabalhoapresentadoem ${ }^{11 \text { th }}$ Annual Boston University Conference on Language Development, Boston, MA. 1986.

Hiramatsu, K. e Lillo-Martin, D. Children Who Judge What They Produce Ungrammatical. In Proceedings of the 22nd Boston University Conference on Language Development: 337-347. 1998.

Lasnik, H. e Crain, S.On the acquisition of pronominal reference. Lingua 65:135154. 1985.

Lust, B., Eisele, J., e Mazuka, R. The Binding Theory Module: Evidence from First Language Acquisition for Principle C. Language 68, 333-358. 1992.

Lust, B., Loveland, K., e Kornet, R. The Development of Anaphora in First Language. Linguistic Analysis 6, 217-249. 1980.

May, R 1985. Logical form.Its structure and derivation. Cambridge, Mass.: MIT Press. McDaniel, D. e Cairns, H. Eliciting Judgments of Grammaticality and Reference.In Methods for Assessing Children's Syntax. MIT Press: Cambridge, MA. 1996. McDaniel, D, Cairns, H. e Hsu, J. Control Principles in the Grammars of Young Children. Language Acquisition 1, 297-335. 1991.

O'Brien, K., Grolla, E. e Lillo-Martin, D. Long Passives are Understood by Young Children. In Proceedings of the 30th Annual Boston University Conference on Language Development, Boston, MA: 441-451. 2005.

Solan, L. Anaphora in Child Language.1978. Tese de Doutorado, University of 
Massachusetts, Amherst.

Tavakolian, S. Structural Principles in the Acquisition of Complex Sentences. 1977. Tese de Doutorado, University of Massachusetts, Amherst.

Thornton, R., e Wexler, K. Principle B, VP Ellipsis, and Interpretation in Child Grammar. Cambridge, MA: MIT Press. 1999.

\section{ANEXO \\ SENTENÇAS USADAS NOS EXPERIMENTOS}

\section{CONDICÃO 1}

TJG: 1. *Ela ${ }_{\mathrm{i}}$ está ensaboando a aranha ${ }_{\mathrm{i}}$.

2. *Ele $e_{i}$ está coçando o cachorro ${ }_{i}$.

TJVV: 3. *Ele $e_{i}$ está lavando o elefante ${ }_{i}$.

4. * Ela $_{\mathrm{i}}$ está escovando a pata $\mathrm{i}_{\mathrm{i}}$.

\section{CONDICÃO 2}

TJG: 5. *Ele $e_{i}$ buzinou quando o cachorro ${ }_{i}$ andou de carro.

6. *Ele $e_{i}$ tirou o chapéu quando o cachorro ${ }_{i}$ andou de patinete.

TJVV: 7. *Ele ${ }_{i}$ coçou a cabeça quando o monstro fez a prova.

8. *Ela ${ }_{i}$ perdeu o sapatinho quando a cinderela ${ }_{i}$ desceu a escada.

\section{CONDICÃO 3}

TJG: 9. Quando ela $a_{\mathrm{i}}$ estava no bosque, a moça $a_{\mathrm{i}}$ sentou embaixo da árvore.

10. Quando ela $a_{i}$ terminou de arrumar a casa, a pata foi cozinhar.

TJVV: 11. Quando ele terminou o banho, o elefante $e_{i}$ tomou café.

12. Quando ele $e_{i}$ acordou, o urso $\mathrm{f}_{i}$ foi a pescar.

* Gostaria de agradecer às crianças alunas da EMEI Monte Castelo, situada no bairro do Butantã, em São Paulo, capital, pela participação em nossos experimentos. A presente pesquisa não teria sido possível sem a participação delas. Agradeço também à direção da escola, às professoras e aos pais das crianças pela hospitalidade com que nos receberam. Gostaria também de agradecer aos dois pareceristas anônimos da Relin pelas críticas e sugestões. Todos os erros que ainda permanecem são de minha inteira responsabilidade. Essa pesquisa 
foi financiada pela FAPESP, processo n. 2007/03624-4.

'Para a discussão apresentada aqui, assumimos que o domínio de regência de uma categoria é a oração em que tal categoria se encontra. "Ser ligado" significa ser c-comandado por um antecedente e ser coindexado com ele. "Ser livre" significa não ser ligado. Por fim, a noção de c-comando utilizada aqui é definida como: "Um nódulo A c-comanda um nódulo $\mathrm{B}$ se e somente se o primeiro nódulo ramificado $\mathrm{C}$ que domina $\mathrm{A}$ também domina B (e A não domina B)" (May, 1985).

iiO contraste em (7) é análogo àquele apresentado em (5) para o português.

iiié importante observar que mesmo crianças de 2;6 anos de idade já são capazes de entender a noção de "verdadeiro" e "falso" e podem, portanto, participar da TJVV.

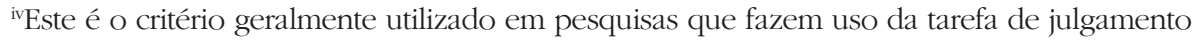
de gramaticalidade (cf., McDaniel e Cairns (1996)). Devido a uma tendência chamada de "yes bias" (em que o sujeito tende a dizer "sim" quando está confuso sobre a gramaticalidade de uma sentença), é geralmente assumido que é mais fácil dizer "sim" numa sessão experimental do que dizer "não". Para termos certeza de que as crianças testadas são capazes de dizer "não", exigimos que elas rejeitem todas as sentenças inaceitáveis. Dessa forma, temos mais garantias de que os sujeitos participantes não têm essa tendência ao "yes bias".

"Dadas duas possibilidades de resposta, "sim" e "não", as crianças responderiam aleatoriamente uma ou outra, originando $50 \%$ de cada tipo de resposta.

viNão discutiremos em detalhes o nó específico em que esse adjunto é colocado na árvore. Para os nossos propósitos, qualquer nó acima de TP traz a configuração desejada.

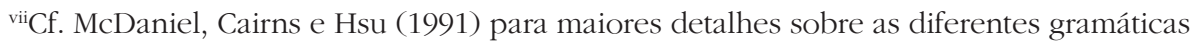
associadas a cada período de desenvolvimento.

viii Cf. Adler (2006) para uma discussão sobre como a criança avançaria em seu desenvolvimento e adquiriria a gramática adulta.

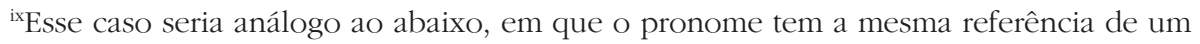
DP, mesmo não estando na mesma sentença que ele:
A:
Cadê o João $\mathrm{O}_{\mathrm{i}}$ ?
B: $\quad$ Ele $_{i}$ saiu.

${ }^{x}$ Note que o estudo de Adler (2006) não investigou o comportamento das crianças com sentenças encaixadas completivas. Em nosso novo estudo, tal lacuna será sanada.

Data de submissão: 12/03/2012

Data de aprovação: 13/05/2012 